\title{
Vibration Analysis of Cracked Cantilever Beam with Varying Crack Length
}

\author{
Dr. Amit M. Patil ${ }^{1 *}$, Amol M. Kolhe ${ }^{2}$, Chetanraj D. Patil ${ }^{3}$ \\ ${ }^{1}$ Assistant Professor, Zeal College of Engineering and Research, Narhe, Pune, India \\ ${ }^{2}$ Assistant Professor, MIT Academy of Engineering, Alandi (D.), Pune, India \\ ${ }^{3}$ Assistant Professor, D.Y .Patil Institute of Technology, Pimpri, Pune, India
}

DOI: $10.36348 /$ sjet.2020.v05i05.006 $\quad$ | Received: 18.05.2020 | Accepted: 26.05.2020 | Published: 30.06 .2020

*Corresponding author: Dr. Amit M. Patil

\section{Abstract}

Engineering structures such as plates, beams, and shells are subjected to different types of loads when used in applications such as bridges, buildings, and other structures. Due to the nature of loading cracks are produced in these elements over a period of time. These cracks will cause the failure of beams due to vibration. Vibration analysis is important to find the natural frequency of the structures. Modal analysis is performed to find the mode shapes and natural frequency of the cantilever beam. In the present investigation, a cantilever beam with crack is modeled and natural frequency for the first three modes is determined by using Ansys Workbench 19.2. The goal of the study is to change the length of the crack along the width of the beam and its effect on the natural frequency of the cantilever beam. During the study, the crack width is kept constant while the depth of crack is varied along with a change in the length of the crack. The crack with depth $45 \mathrm{~mm}$ and crack of length $50 \mathrm{~mm}$ gives a lower value of natural frequency.

Keywords: Beam; crack; depth; frequency; mode.

Copyright @ 2020: This is an open-access article distributed under the terms of the Creative Commons Attribution license which permits unrestricted use, distribution, and reproduction in any medium for non-commercial use (NonCommercial, or CC-BY-NC) provided the original author and source are credited.

\section{INTRODUCTION}

Modal analysis is the process of finding out the dynamic characteristics of a system in terms of natural frequencies, damping factors, and mode shapes, etc. For a cracked structure like beam modal analysis is important to find out the effect of cracks on natural frequencies. The cantilever beam is one of the widely used structural elements. This beam is subjected to cracks or internal voids due to material irregularity causing failure of the beam. Different types of cracks are discussed by M. Kiran Kumar et al., [1] this study highlights the area of structural discontinuity and its effect on the structural member. Md. Shumon Miaa et al., [2] investigated mode shapes of the uncracked and cracked cantilever beam to find out mode shape. Abaqus has been used as a finite element package with different mesh sizes. Effect of crack depth and crack opening size on natural frequency has been studied and concluded that the natural frequency reduces with the crack. Priyanka P. Gangurde et al., [3] had studied vibration characteristics of a cantilever beam, simply supported beam with different materials. They have a modelled beam with a triangular crack at a distance of 100 to $250 \mathrm{~mm}$ resulting that natural frequency reduces with the increment in crack depth. Vaibhav Ghodge et al., [4] modelled vibration analysis of cantilever beam with mass at free and simply supported beam with mass at the center. A comparative study is made of four different materials. The study with the unloaded condition and loaded condition revels that the natural frequency increases for structural steel rather than the other three materials. Dr. K. B. Waghulde et al., [5] performed an experimental investigation of cracked aluminum cantilever beam resulting that when crack depth has increased the frequencies of vibration of cracked beams decrease for any part of the beam due to reduction in the stiffness of the beam. The study is performed for multiple cracks showing that the natural frequency of beam reduces as umber of crack is increased. C. Ramachandran et al., [6] used ANSYS APDL for modelling the cracked cantilever beam. The aim of the study is to simulate the effect of cracks at various locations such as $0.1 \mathrm{~m}, 0.15 \mathrm{~m}, 0.2 \mathrm{~m}, 0.25 \mathrm{~m}$, $0.3 \mathrm{~m}, 0.35 \mathrm{~m}, 0.4 \mathrm{~m}$ and $0.45 \mathrm{~m}$ from the fixed end of the beam. The result shows that the natural frequency is affected by the position of crack i.e. as the crack location is moved further the natural frequency of bema is reduced. Rupali Patil et al., [7] performed an investigation of a cracked and uncracked cantilever beam with different techniques such as analytical 
formulation, Finite element analysis using ANSYS and experimental technique. The natural frequencies of these studies with all aforesaid methods are closely in agreement with each other. The study has also extended with a new approach of Fuzzy logic for finding the correct value of crack size and crack location. Since crack location and crack depth are affecting the natural frequency of the beam. Malay Quila et al., [8] performed a modal analysis of cracked and uncracked cantilever beam with a change in crack position and crack depth. The result shows that the position of crack and crack depth affects the amplitude of frequency. M. Kiran Kumar et al., [1] have performed a similar study as that of [8] and results indicate that when crack depth is changed from $5 \mathrm{~mm}$ to $15 \mathrm{~mm}$ the natural frequency reduces.

Chaudhari J. R. [9] performed an investigation of cracked cantilever beam and static structural analysis. The beam has been modelled with Solid 185 with element type as tetrahedral. The study is performed for varying beam lengths as of $100 \mathrm{~mm}$ and $200 \mathrm{~mm}$ while crack depth is considered as $1 \mathrm{~mm}$ and $2 \mathrm{~mm}$. Cracked beam with more depth the amplitude reduces but natural frequency increases, while the increase in crack location for given depth amplitude reduces but natural frequency increases. P. Yamuna et al. [10] modelled simply supported beam with crack and performed modal analysis and the first five frequencies are recorded. The meshed model obtained using the SOLID 186 tetrahedral 20 node brick element. The boundary conditions considered as crack depth changed from $10 \mathrm{~mm}$ to $15 \mathrm{~mm}$ with a step of $0.5 \mathrm{~mm}$ while the crack location is changed from $100 \mathrm{~mm}$ to $450 \mathrm{~mm}$ and changed with a step of $50 \mathrm{~mm}$. The lower value of frequency is obtained at the middle of beam.

Rane H. S. et al., [11] performed free vibration analysis of cantilever beam with conditions such as crack depth $1 \mathrm{~mm}, 2 \mathrm{~mm}, 3 \mathrm{~mm}$ and location of $150 \mathrm{~mm}$, $300 \mathrm{~mm}, 450 \mathrm{~mm}$ from the fixed end. With constant location of crack depth increases but the natural frequency of the beam decreases. Based on various researchers' contribution, it has been seen that the modal analysis is performed with cantilever beam and simply supported beam. The cracked and uncracked beams are studied and natural frequencies are obtained. The study is focused with change in crack depth, change in position of crack and size of crack opening with constant crack length along the width of beam but not much attention is paid towards change in length of crack and its effect on natural frequency of beam.

\section{Numerical Modelling Approach}

The objective modal analysis is to find out the frequency at which the beam vibrates. When a cracked beam or other structure starts vibrating i.e. the natural frequency of beam is equal to the frequency of the applied load. The boundary conditions applied will decide the behavior of beam when it starts vibrating at a number of mode shapes. In the present study, a structural steel cantilever beam with length $1000 \mathrm{~mm}$, width $150 \mathrm{~mm}$ and depth $80 \mathrm{~mm}$ is taken. An open triangular crack along the width is modelled with varying crack length as $30 \mathrm{~mm}, 60 \mathrm{~mm}, 90 \mathrm{~mm} \mathrm{120}$, and $15 \mathrm{~mm}$. The crack depth is $15 \mathrm{~mm}$ and $30 \mathrm{~mm}$, and 45 $\mathrm{mm}$ while the crack opening size is considered as $2 \mathrm{~mm}$ while the position of crack from the fixed end of the beam is taken as $150 \mathrm{~mm}, 300 \mathrm{~mm}, 450 \mathrm{~mm}, 600 \mathrm{~mm}$, and $750 \mathrm{~mm}$. The beam parameters are shown in Table1.

Table-1: Beam Parameters

\begin{tabular}{|l|l|}
\hline Parameter & Value \\
\hline Length & $1000 \mathrm{~mm}$ \\
\hline Width & $150 \mathrm{~mm}$ \\
\hline Depth & $80 \mathrm{~mm}$ \\
\hline Material: & Structural Steel \\
\hline Elastic Modulus & $7.1 \times 10^{10} \mathrm{~N} / \mathrm{mm}^{2}$ \\
\hline Density & $7560 \mathrm{Kg} / \mathrm{m}^{3}$ \\
\hline Poissons Ratio & 0.3 \\
\hline
\end{tabular}

\section{Crack Modelling}

The finite element analysis formulation is used for the modal analysis of a cantilever beam. The analysis is performed with Ansys Workbench 2019 R3 Student version. The crack opening size is $2 \mathrm{~mm}$ for all three crack depths. A total of 15 CAD Models are prepared in Catia for analysis. Meshing is performed by varying mesh size from 7 to $10 \mathrm{~mm}$ with an increment of $0.5 \mathrm{~mm}$ for grid independence and results are similar. But due to the limitation of a maximum number of nodes finer mesh size has not been chosen. Finally, the discretization is performed with a global mesh size of 7 $\mathrm{mm}$.

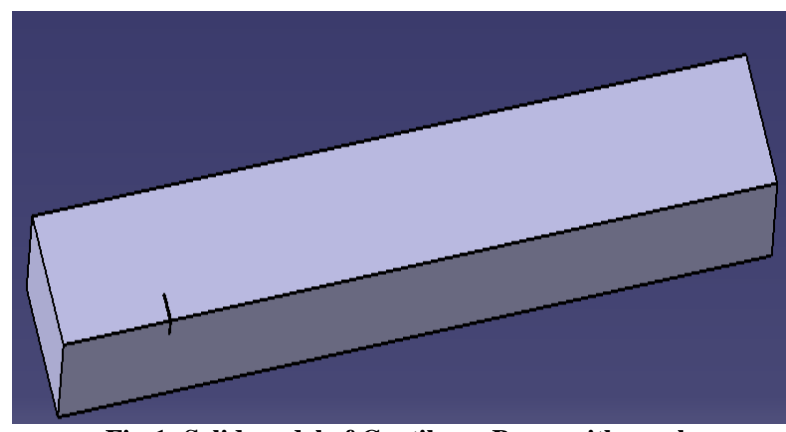

Fig-1: Solid model of Cantilever Beam with crack 
Amit M. Patil et al., Saudi J Eng Technol, May, 2020; 5(5): 251-257

RESULTS AND DISCUSSION

In this analysis, we are considering three cases such as 1. Crack depth $15 \mathrm{~mm} \mathrm{2.} \mathrm{Crack} \mathrm{depth} 30 \mathrm{~mm}$ and 3. Crack depth $45 \mathrm{~mm}$

\section{Case-1}

Crack depth $15 \mathrm{~mm}$, here the crack location is changed from $150 \mathrm{~mm}$ to $750 \mathrm{~mm}$ with the step of
$150 \mathrm{~mm}$ as shown from Figure-2 to Figure-6. It shows that the lowest value of frequency is $389.11 \mathrm{~Hz}$ for mode 3 when the crack is located at $450 \mathrm{~mm}$ from fixed end of beam. With the increment in the crack length, the frequency gets lower. The mode 1 value varies from 65 $\mathrm{Hz}$ and up to $64 \mathrm{~Hz}$ while mode 2 values are close to $120 \mathrm{~Hz}$.

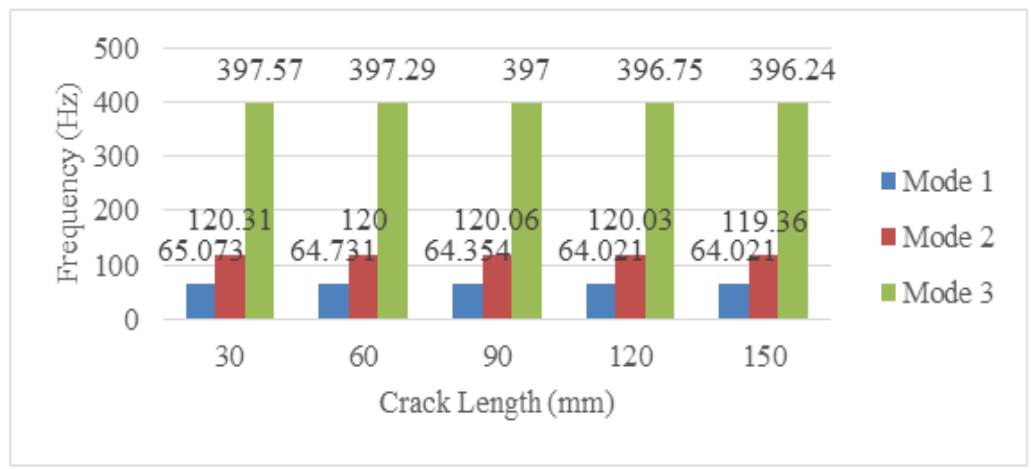

Fig-2: Frequency with crack depth $15 \mathrm{~mm}$ and crack located at $150 \mathrm{~mm}$

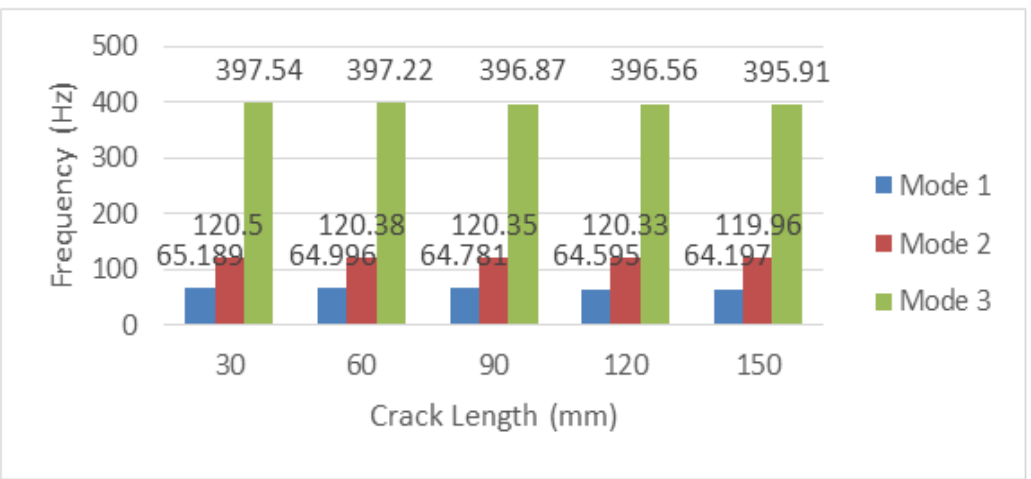

Fig-3: Frequency with crack depth $15 \mathrm{~mm}$ and crack located at $300 \mathrm{~mm}$

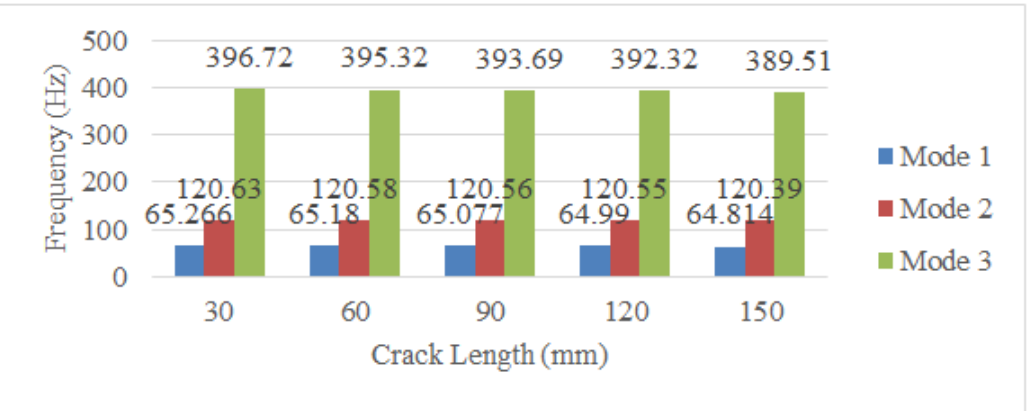

Fig-4: Frequency with crack depth $15 \mathrm{~mm}$ and crack located at $450 \mathrm{~mm}$

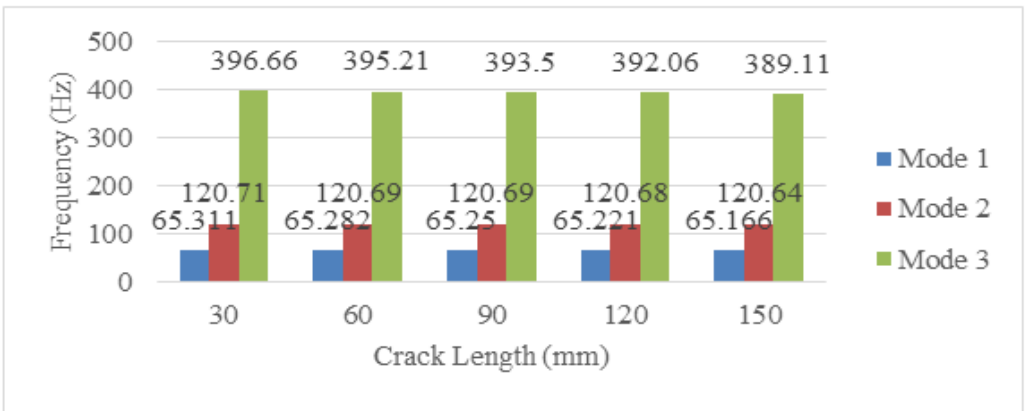

Fig-5: Frequency with crack depth $15 \mathrm{~mm}$ and crack located at $600 \mathrm{~mm}$ 


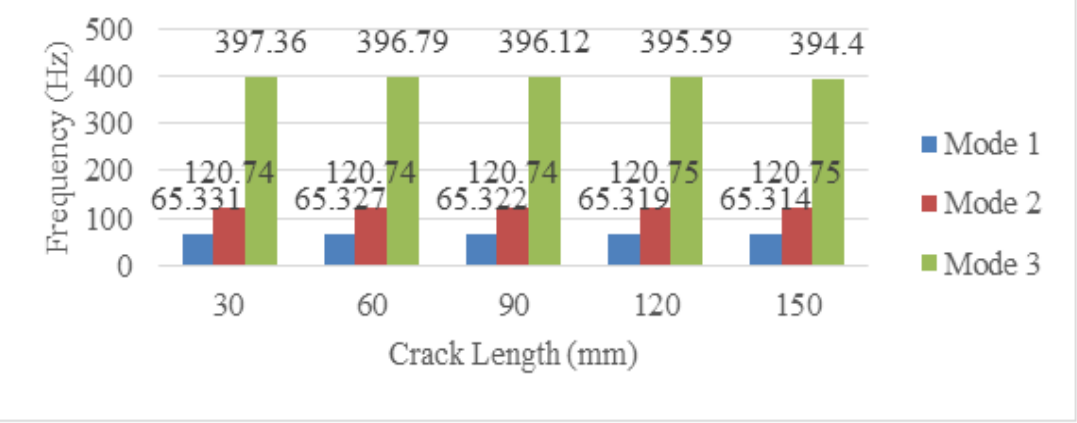

Fig-6: Frequency with crack depth $15 \mathrm{~mm}$ and crack located at $750 \mathrm{~mm}$

\section{Case-2}

Crack depth $30 \mathrm{~mm}$ Figure 7 to Figure 11 gives various positions of the crack along the width of the beam. It shows that the lowest value of frequency is $57.72 \mathrm{~Hz}$ for mode 1 when the crack is located at
$150 \mathrm{~mm}$ from fixed end of beam. The change in the crack depth has reduced the frequency of more than $15 \mathrm{~mm}$ depth. The mode 1 value varies from $64 \mathrm{~Hz}$ and up to $57 \mathrm{~Hz}$ while mode 2 values are lying from $120 \mathrm{~Hz}$ to $115 \mathrm{~Hz}$.

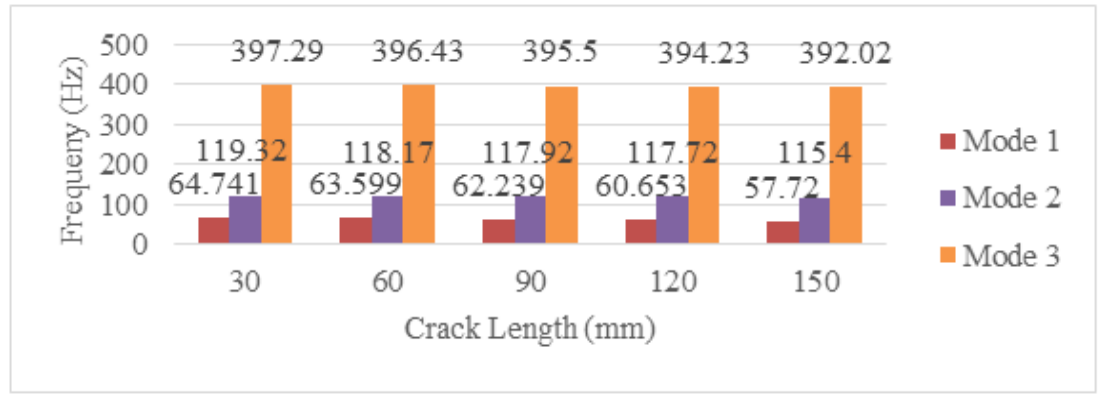

Fig-7: Frequency with crack depth $30 \mathrm{~mm}$ and crack located at $150 \mathrm{~mm}$

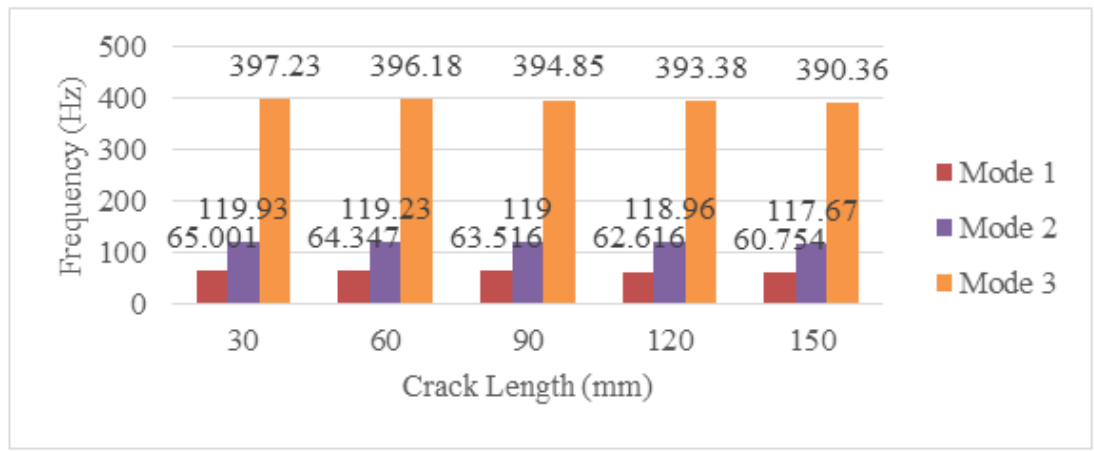

Fig-8: Frequency with crack depth $30 \mathrm{~mm}$ and crack located at $300 \mathrm{~mm}$

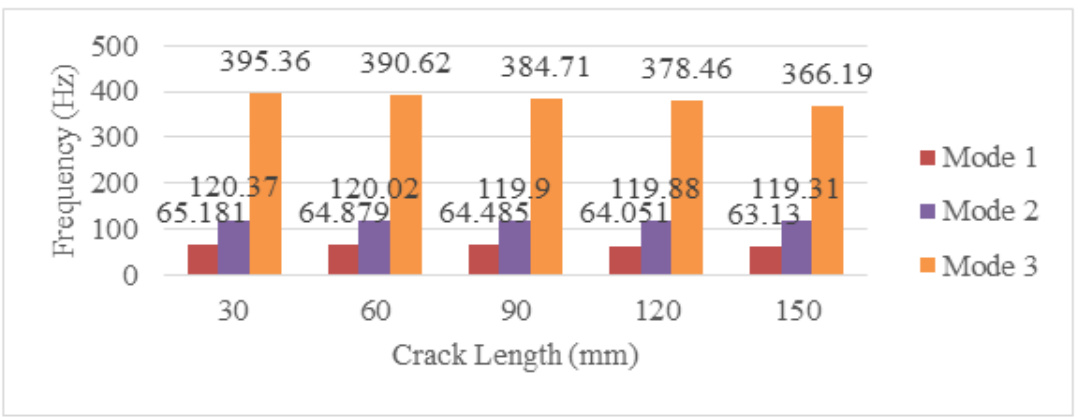

Fig-9: Frequency with crack depth $30 \mathrm{~mm}$ and crack located at $450 \mathrm{~mm}$ 


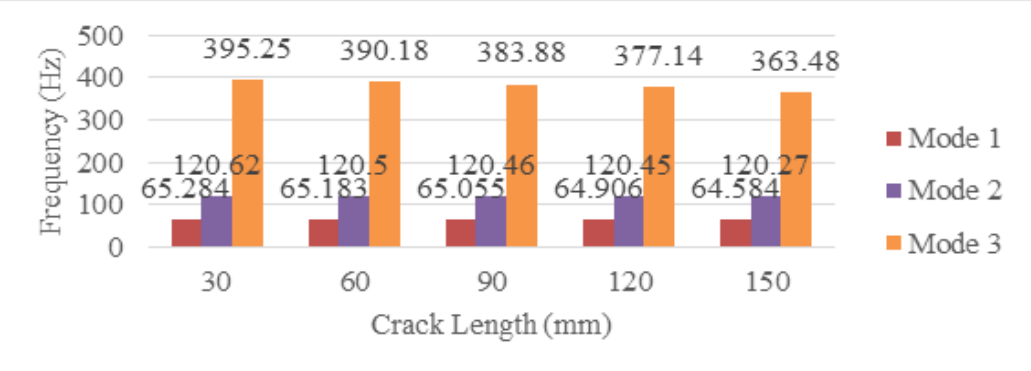

Fig-10: Frequency with crack depth $30 \mathrm{~mm}$ and crack located at $600 \mathrm{~mm}$

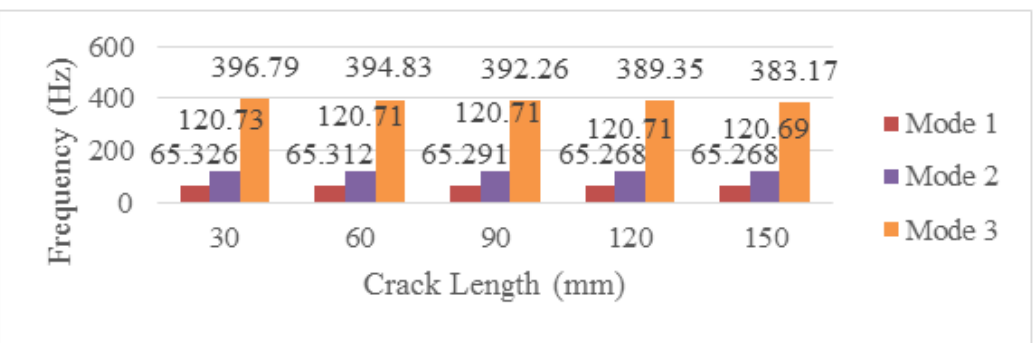

Fig-11: Frequency with crack depth $30 \mathrm{~mm}$ and crack located at $750 \mathrm{~mm}$

\section{Case-3}

Crack depth $45 \mathrm{~mm}$ Figure 12 to 16 represents the different locations of crack on beam width. It shows that the lowest value of frequency is $47.6 \mathrm{~Hz}$ for mode 1 when the crack is located at $150 \mathrm{~mm}$ from the fixed end of the beam. The change in the crack depth has reduced the frequency more than case 1 and case 2 of analysis. The crack length as of $150 \mathrm{~mm}$ and for all the locations of crack shows a much lower value of natural frequency in comparison with all other analysis results.

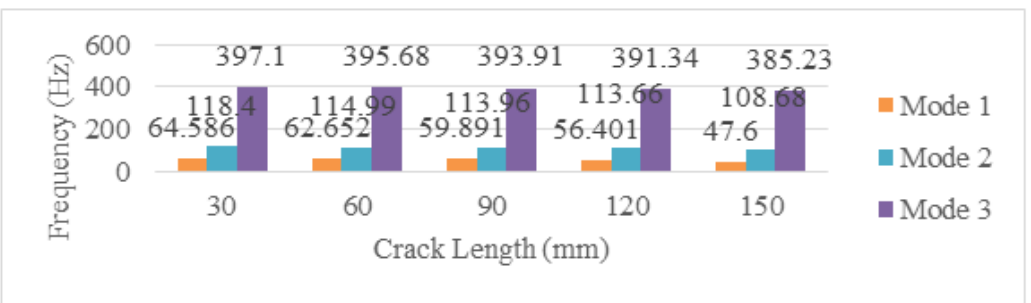

Fig-12: Frequency with crack depth $45 \mathrm{~mm}$ and crack located at $150 \mathrm{~mm}$

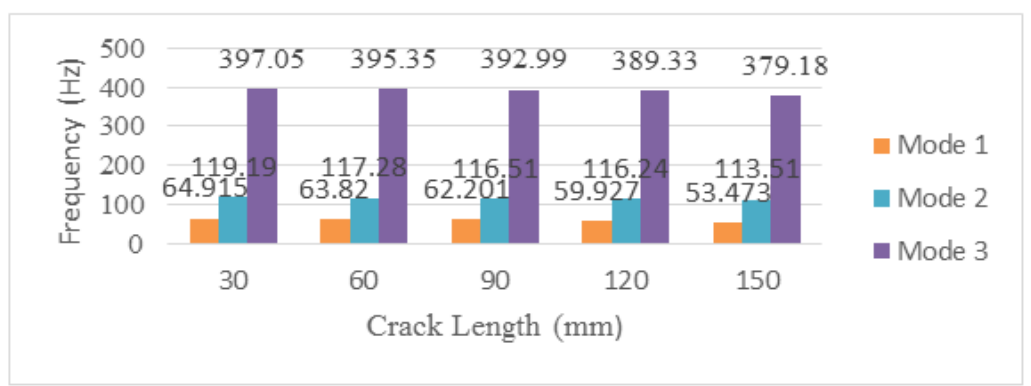

Fig-13: Frequency with crack depth $45 \mathrm{~mm}$ and crack located at $300 \mathrm{~mm}$

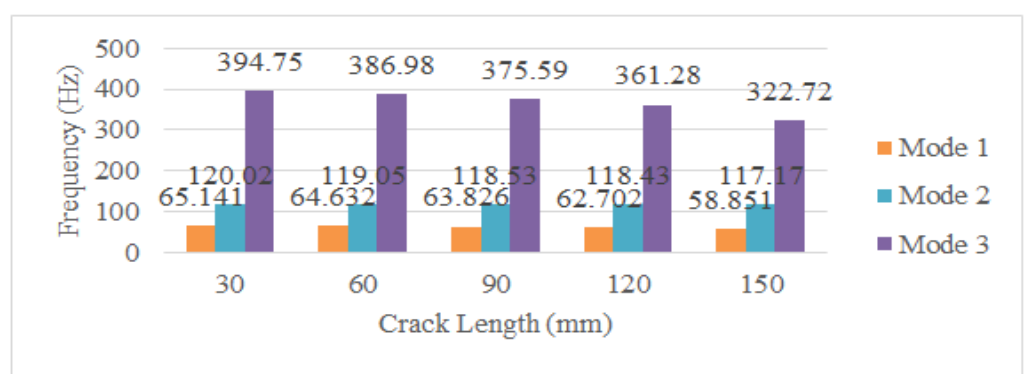

Fig-14: Frequency with crack depth $45 \mathrm{~mm}$ and crack located at $450 \mathrm{~mm}$ 


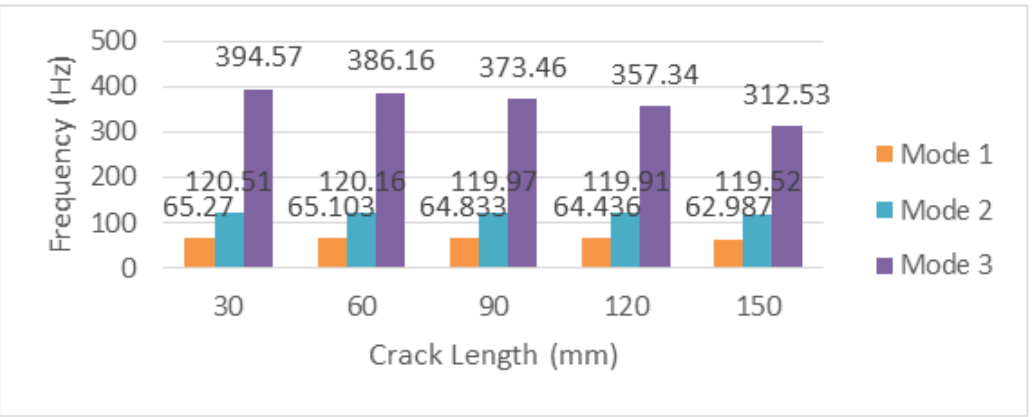

Fig-15: Frequency with crack depth $45 \mathrm{~mm}$ and crack located at $600 \mathrm{~mm}$

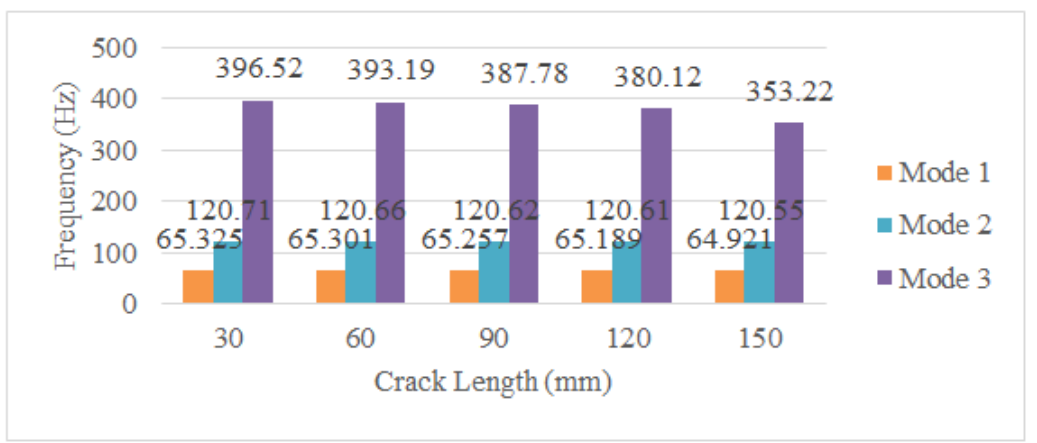

Fig-16: Frequency with crack depth $45 \mathrm{~mm}$ and crack located at $750 \mathrm{~mm}$

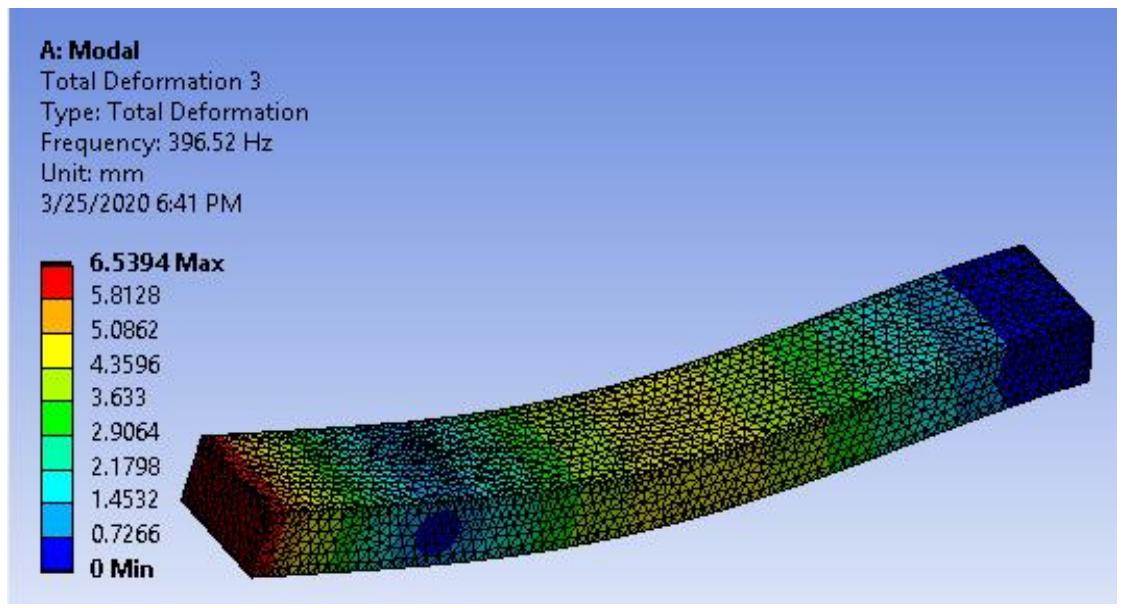

Fig-17: Mode shape at third Mode

\section{CONCLUSION}

The crack opening size will affect significantly the natural frequency of the beam. As suggested by [2] we had chosen a small crack opening size as $2 \mathrm{~mm}$. The change in the crack depth affects the natural frequency as the lowest frequencies are obtained for $45 \mathrm{~mm}$ crack depth than $15 \mathrm{~mm}$ and $35 \mathrm{~mm}$. The crack position also affects the frequency as crack distance from fixed increases the frequency reduces for different modes. The current investigation is much focused on the effect of different lengths of crack on natural frequency. It has been observed that for larger crack length the frequency is lower for all three crack depths under study. Mesh refinement will give more accurate results for all cases since due to computational limitation this study has not performed and can be undertaken in the future. Further research can be extended by an Experimental approach.

\section{REFERENCES}

1. Kumar, M. K., Pasha, M. A., Khan, M. A., \& Nagaraju, C. N. (2018). Modal Analysis of a Cracked Cantilever Beam Using ANSYS Workbench. International Journal of Prevention and Control of Industrial Pollution, 4(1), 24-30.

2. Mia, M. S., Islam, M. S., \& Ghosh, U. (2017). Modal analysis of cracked cantilever beam by finite element simulation. Procedia engineering, 194, 509-516.

3. Priyanka, P. G., \& Santosh, N. S. Vibration Analysis of Cracked Beam: A Comparative Study, International Engineering Research Journal, 12821288.

4. Vaibhav Ghodge, A. P., \& Bhattu, S. B. P. (2018). Vibration Analysis of Beams, International 
Journal of Engineering Trends and Technology, $55,81-86$.

5. Waghulde, K. B., \& Kumar, B. (2014). Vibration analysis of cracked cantilever beam with suitable boundary conditions. International Journal of Innovative Science, Engineering and Technology, 1(10), 20-24.

6. Ramachandran, C., \& Ponnudurai, R. (2017). Modal Analysis of Beam with Varying Crack Depth. International Journal of Engineering Research and Technololgy, 452-458.

7. Patil, R. R., \& Verma, D. (2016). Free Vibrational Analysis of Cracked and Un-cracked Cantilever Beam. International Research Journal of Engineering and Technology (IRJET), 3(2), 260277.
8. Quila, M., Mondal, S. C., \& Sarkar, S. (2014). Free vibration analysis of an un-cracked \& cracked fixed beam. Journal of Mechanical and Civil Engineering, 11(3):76-83.

9. Chaudhari, J. R., \& Patil, C. R. (2016). Study of static and modal analysis of un-crack and crack cantilever beam using FEA. International Journal of Engineering Research, 5(4).

10. Yamuna, P., \& Sambasivarao, K. (2014). Vibration analysis of beam with varying crack location. International Journal of Engineering Research and General Science, 2(6), 1008-1017.

11. Rane, H. S., Barjibhe, R. B., \& Patil, A. V. (2014). Free Vibration Analysis of Cracked Structure. International Journal of Engineering Research \& Technology, 3(2):2816-2822. 